Review

\title{
Wearable Photovoltaic Applications as Energy Sources for Everyday Devices
}

\author{
${ }^{1}$ Afonso da Silva Ravasco, ${ }^{1,2}$ Joao Paulo N. Torres and ${ }^{1,2 *}$ Ricardo Lameirinhas \\ ${ }^{1}$ Department of Electrical and Computer Engineering, Universidade de Lisboa-Instituto Superior Técnico, Portugal \\ ${ }^{2}$ Instituto de Telecomunicac,oes, 1049-001 Lisbon, Portugal
}

\author{
Article history \\ Received: 21-05-2021 \\ Revised: 12-06-2021 \\ Accepted: 15-06-2021 \\ Corresponding Author: \\ Mr. Ricardo Lameirinhas \\ Department of Electrical and \\ Computer Engineering, \\ Universidade de Lisboa- \\ Instituto Superior Técnico, \\ Portugal \\ Email: ricardo.lameirinhas@tecnico.ulisboa.pt
}

\begin{abstract}
Solar technology since its first implementation for energy production has evolved in numerous directions to become part of a normal reality in future energy systems. The people's energetic consumption changed as well. In the present days, people use portable devices more than ever, such as mobile phones and laptops and to power these portable devices, batteries are used. But what if we did not use batteries? or what if we could just keep charging our portable devices on the go? Flexible solar cells' efficiency has been increasing throughout the years, especially the perovskite material that in the last years have reached a power conversion efficiency above the $20 \%$ mark. This opened the possibility to tackle other areas that traditional solar cells could not, including the possibility to use solar cells as a wearable source of power for our daily gadgets. Three types of materials will be shown as wearable solar cells and the evolution of perovskite material will be presented in order to set the state-of-art for future works in this domain.
\end{abstract}

Keywords: Optoelectronics, Perovskite Solar Cells, Photoelectric Effect, Photovoltaic Technology, Semiconductors, Solar Energy Conversion

\section{Introduction}

Nowadays, technology and sustainability have never worked so closely. In order to build the future societies and citizens of tomorrow, it is imperative to build and develop future solutions that will make humankind prosper for more generations to come Durão et al. (2020); Melo et al. (2020). The main concern for this sustainable revolution always comes down to future consequences of new technologies to the planet itself, for example the use of fossil fuels without any restriction can lead to an environmental disaster so to correct that problem and to solve a potential energy crisis in the future, solar energy was seen as solution (Isabela et al., 2021; dos Santos et al., 2021). As technology evolves, the needs and demands for people change as well, with one of the best examples being mobile phones. At first, mobile phones were just seen with the solely purpose of making and receiving calls and messages, but along the years mobile phones evolved into smart phones and now we can download and upload various types of files, listen to music, stream videos, etc. This example proves that batteries were not able to evolve as fast as our energy demands for portable technology, which opens a lot of doors for new solutions.
Wearable technology or smart wear is a concept which resulted from the evolution of mechanical devices to intelligent systems that can monitor vital signs, biological signals and any type of sensory feedback. The term started to gain some traction once Apple and Samsung started developing their own watches to scan biometric signals for fitness and health purposes Huaroto et al. (2020); Nanjappan et al. (2017). Most of the devices that we deem necessary nowadays must have mobile accessibility (such as mobile phones and laptops) together with a sufficient power supply to last at least one working day. So, the key is operating at low voltages.

Flexible solar cells can be a potential solution for charging or powering these devices throughout the day. The perovskite solar cells can offer a potential solution to the problem at hand since it is possible to achieve a very generous efficiency to power such devices. Yang et al. (2019); Zhang et al. (2018); Isabela et al. (2021); dos Santos et al. (2021); Engana Carmo et al. (2021).

\section{Electrical Properties of a p-n Junction}

The $p-n$ junction is commonly used for solar cells. This junction creates a charge separation of electron and holes and when the junction is formed, the large carrier 
concentration gradients cause the diffusion of carriers, i.e., holes diffuse from p-type semiconductors to n-type semiconductors and electrons diffuse from the way around. Because of the ionized impurity atoms, a layer without mobile charge carriers is formed when the electrons and holes diffuse across the junction, hence creating an electric field in this area which is called the depletion region (Batista et al., 2012); Soga et al., 2006; Duarte et al., 2021; Isabela et al., 2021; dos Santos et al., 2021).

At thermal equilibrium, the Fermi levels of the p-type semiconductor and n-type semiconductor are equal as it can be seen in Fig. 1.

\section{p-n Junctions as Solar Cells}

A Photovoltaic (PV) solar cell is responsible for solar irradiance conversion into electrical energy. It can be composed by a simple $p-n$ junction like a diode. The $p-n$ junction has a photoconductive behavior, to which it is called photodiode.

The photodiode can be either a passive or active device, which respectively translates into a photoreceptor and a PV cell. The $I(V)$ curve of the PV cell under no source of light, behaves exactly as a diode, but once it is illuminated it sparks an offset in the current, as it can be seen in Fig. 2 and mathematically presented as expression 1 . This current is called the photogenerated current $I_{L}$, created by the generation of electron-hole pairs due to the incident light. This current is proportional to the light intensity Labouret et al. (2010); Duarte et al. (2021); Isabela et al. (2021); dos Santos et al. (2021). In that expression, $I_{\text {is }}$ represents the inverse saturation current of the $p$ - $n$ junction, $n$ its ideality-factor and $V_{t}$ the thermal voltage.

Given the previous equation, an ideal model of a PV cell the equivalent circuit can be given by the Fig. 3. In this Figure, it is possible to observe the representation of the $p$ - $n$ junction through the ideal diode and the external light source given by the current source, $I_{L}$ Labouret et al. (2010); Soga et al. (2006).

Once again in Fig. 2 it is possible to point out the produced curve under illumination is shifted by a factor of $I_{L}$. This value of $I_{L}$ can be better perceived as (approximately) the short-circuit current, $I_{S C}$, since it is the generated current for a zero-input voltage. Another important point in this curve is the $\mathrm{V}_{\mathrm{OC}}$ voltage, which denotes the point where the PV cell's current reaches zero, hence the denomination open-circuit voltage. These two values are very important, since the play a major role in the definition of the solar cell's $I(V)$ characteristic. Soga et al. (2006) On a side note, Equation 1 is usually the way current-voltage curves behave. However, to be more convenient, the $I(V)$ curve of the solar cell is plotted on the $1^{\text {st }}$ quadrant, changing only the sign of the current. With this statement in mind, it is possible to rewrite the expression as presented on 2 .
Through this equation it is possible to obtain the short- circuit current, $I_{S C}$, which is given by expression 3 and the open circuit voltage is described as presented on expression 4:

$$
\begin{aligned}
& I(V)=I_{i s}\left(e^{\frac{v}{n V_{t}}}-1\right)-I_{L} \\
& I(V)=I_{L}\left(e^{\frac{v}{n V_{t}}}-1\right) \\
& I_{S C} \approx I_{L}, \text { for } V=0 \\
& V_{O C}=V_{T} \ln \left(1+\frac{I_{L}}{I_{s}}\right)
\end{aligned}
$$

However, solar cells contain certain defects that prohibits them to be ideal. For instance, the resistance $\left(R_{S}\right)$ along the copper wiring and contacts of the $P V$ cell plays a major role in the shape of the $I(V)$ curve, which is usually depicted as a resistor in series with the cell at hand. There is also another type of influence due to any current leakage, which is certain fractions of current are loss to ground, usually depicted as a parallel resistance to the cell called the shunt resistance $\left(R_{s h}\right)$. The equivalent model is presented in Fig. 4, which is mathematically described by expression 5 .

$I=I_{L}-I_{s}\left(e^{\frac{q\left(I . R_{s}+V\right)}{n V_{T}}}-1\right)-\frac{I \cdot R_{s}+V}{R_{s h}}$

\section{Wearable Solar Cell Technology}

Wearable technology is still a recent topic in the PV world, but nevertheless, it has sparked some interest in the scientific community. The main objective for PV technology to become wearable is mainly seen by its ability to power portable electronics, such as smart watches, smart phones, or laptops, since most of these devices require very small voltages to function properly.

Flexible solar cells can be a solution to implement this new reality and given the different types of material at our disposal, it is possible to develop different approaches to the problem (Bernardes et al., 2021; dos Santos et al., 2021). Some researchers have focused on building actual textile from these photovoltaic materials, but some opted for a more layer deposition on top of a textile substrate kind of approach.

In previous years, some studies were conducted in this field using Dye-Sensitized Solar Cells (DSSC) as a solution for its flexibility, low fabricating costs and also their relatively high efficiency under weak illumination, since everyday objects are not constantly under direct 
lighting. The major feature for selecting the DSSC is the flexibility and its bending ease, because in a real scenario of creating a new type of clothing as a solar power source, it is imperative to select a material that allows to behave like a textile and be robust enough to withstand deformations as the likes of rolling and folding. DSSCs have also sparked a few interests as well, not by its power conversion efficiency because it is not as high as other materials, but it caught the researchers' eye for its lowcost production and (most importantly) small environmental impact (Jamalullail et al., 2018; dos Santos et al., 2021; Isabela et al., 2021).

In the studies conducted by Min Yun, it was developed a textile from different materials, with the main purpose of being sewn into different pieces of fabric, allowing the analysis of the solar cell in a more realistic environment.
In the first experiment, it was taken into consideration the use of different types of fabrics and their performance under 1 Sun illumination. One of these fabrics was Hanji, a traditional Korean paper and the results can be enlightened by the obtained black current density curve in Fig. 5. Figure 6 illustrates Min experiments. Registering an approximate short circuit current of $17 \mathrm{~mA} \mathrm{~cm}{ }^{2}$ and an open circuit voltage of about $0.7 \mathrm{~V}$, resulting in a very low fill factor, FF, of 0.37 and an efficiency of roughly $5.3 \%$, being its only limitation. Silk proved to have a higher impact than the others achieving an efficiency of almost 7\%. Min and her co-workers concluded that there was still room for improvements in the materials used, since they had used conventional and commercially available materials, as well as improvements in the woven pattern, which was later tackled in the future experiments Yun et al. $(2014 ; 2016)$.

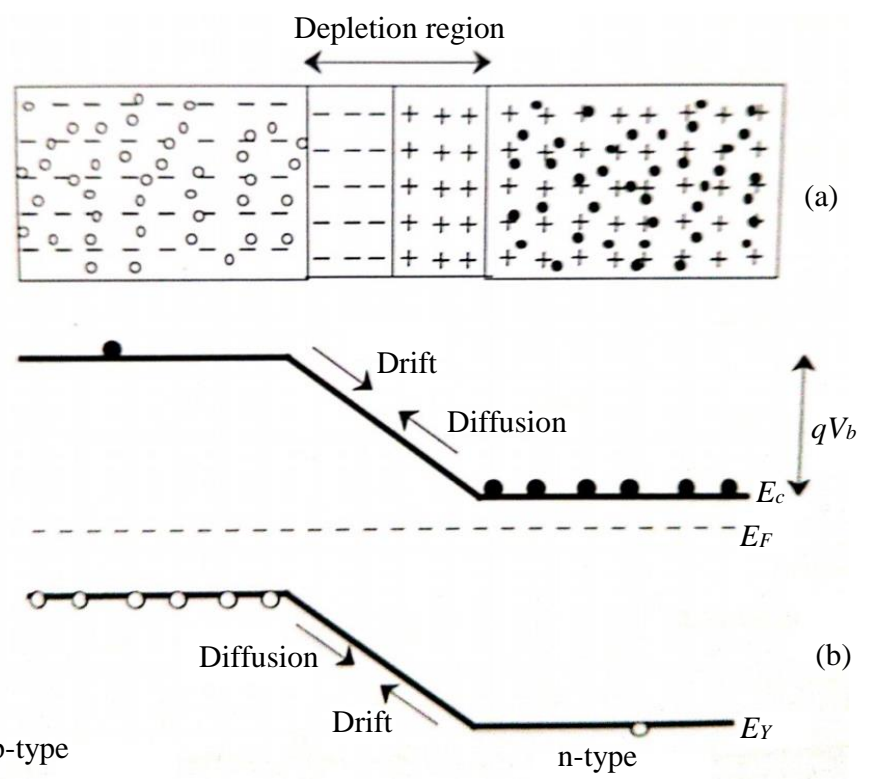

Fig. 1: $p$-n junction band diagram representation, Soga et al. (2006)

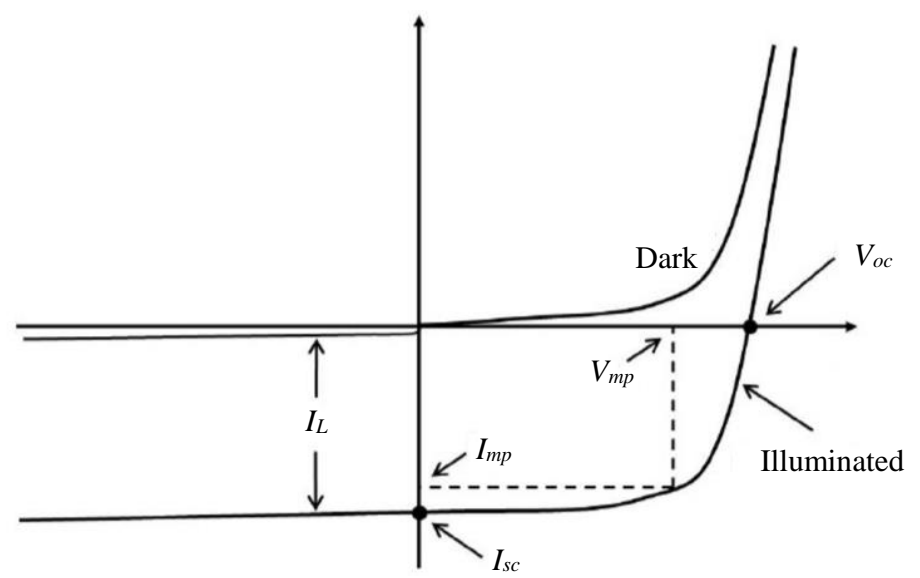

Fig. 2: $I(V)$ curve of a solar cell 


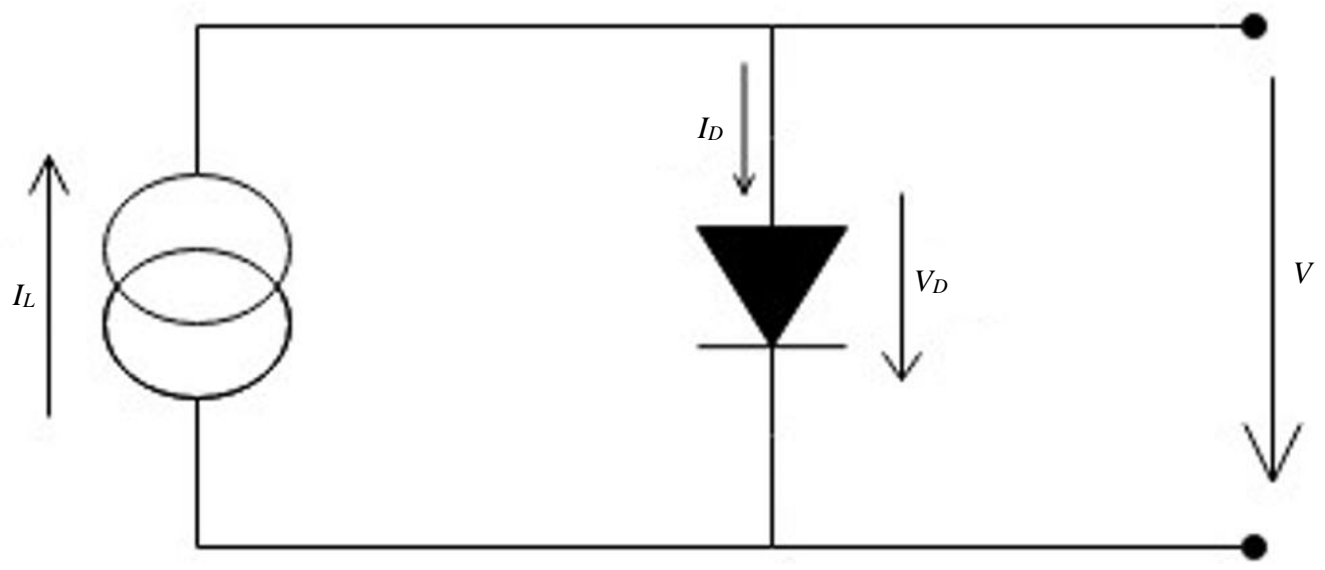

Fig. 3: Solar cell, ideal circuit

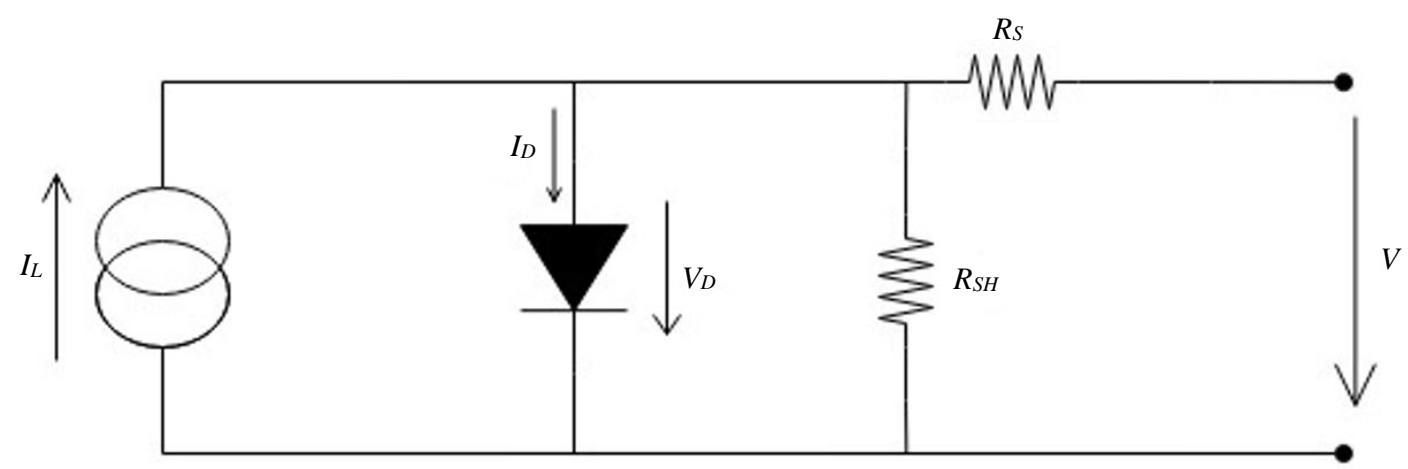

Fig. 4: Real solar cell, depicted by the current leakage and copper losses

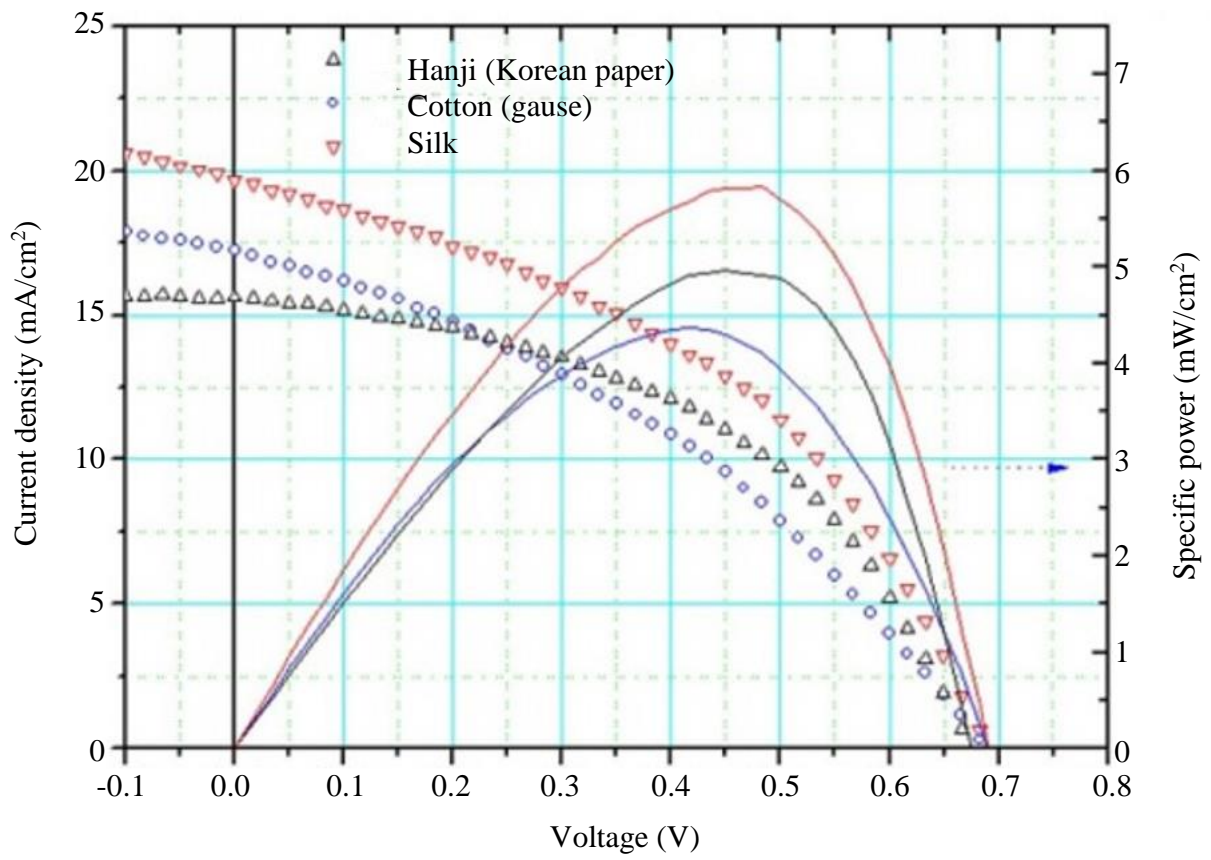

Fig. 5: Current density-voltage characteristic and power-voltage curves for each type of analyzed cloth fabric from Min Yun experiment 


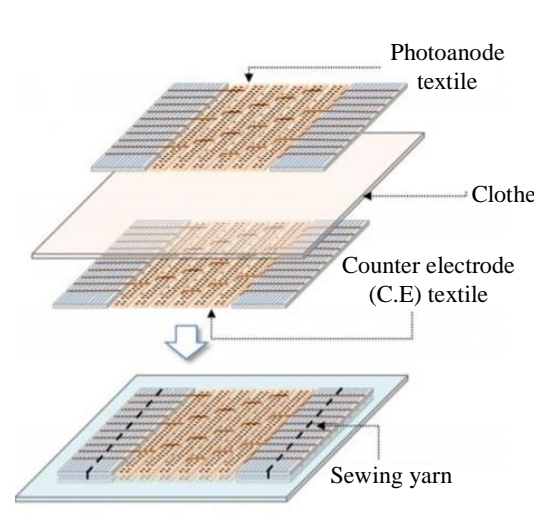

(a)

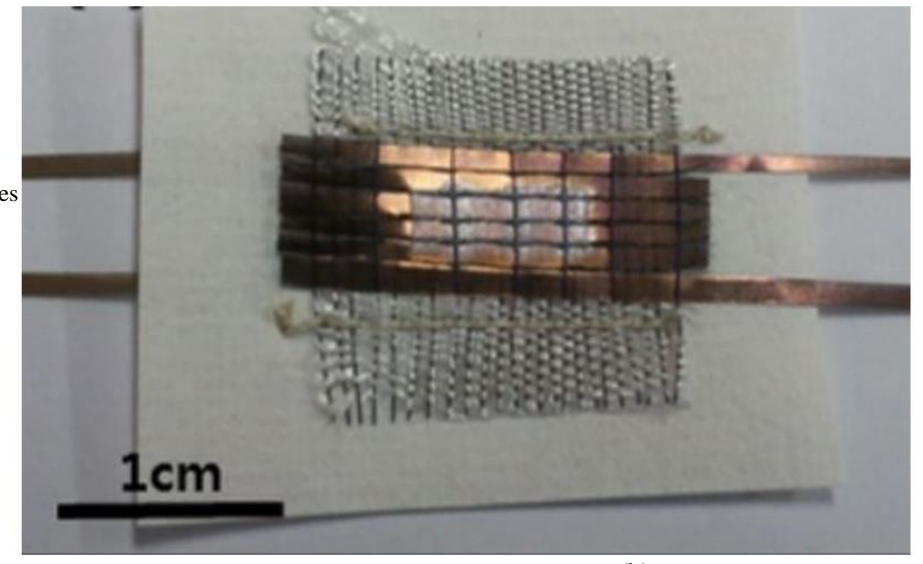

(b)

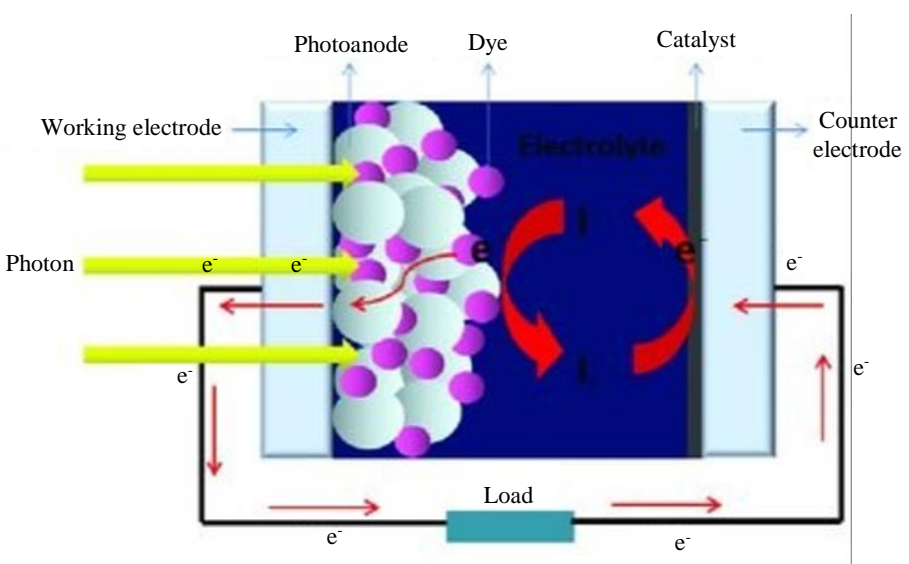

(c)

Fig. 6: a-b Min Yun's experimental results for the creation of a textile-based DSSC. (c) Structure of a DSSC. The injection of photons will be absorbed by the dye, leading to an injection of electrons to in the photoanode layer and later to the electrodes, due to photoexcitation; (a) Illustration of Min Yun's experimental textile-based dye-sensitized solar cell made after sewing textile electrodes to the fabric, Yun et al. (2014); (b) Produced textile-based DSSC after sewing to Hanji paper, Yun et al. (2014); (c) Basic structure and operating principle of DSSCs, Jamalullail et al. (2018)

The use of DSSCs as wearable solar cells unlocked a whole new concept of creating textile materials to enhance the power conversion efficiency, setting new challenges such as the adaptation of some materials used for the different components of DSSCs, like electrodes, electrolytes and so on.

In the studies conducted by Min Yun, it was developed a textile from different materials, with the main purpose of being sewn into different pieces of fabric, allowing the analysis of the solar cell in a more realistic environment. In the first experiment, it was taken into consideration the use of different types of fabrics and their performance under 1 Sun illumination. One of these fabrics was Hanji, a traditional Korean paper and the results can be enlightened by the obtained black current density curve in Fig. 5. Figure 6 illustrates Min experiments. Registering an approximate short circuit current of $17 \mathrm{~mA} \mathrm{~cm}$ and an open circuit voltage of about $0.7 \mathrm{~V}$, resulting in a very low fill factor, FF, of 0.37 and an efficiency of roughly 5.3\%, being its only limitation. Silk proved to have a higher impact than the others achieving an efficiency of almost 7\%. Min and her co-workers concluded that there was still room for improvements in the materials used, since they had used conventional and commercially available materials, as well as improvements in the woven pattern, which was later tackled in the future experiments Yun et al. $(2014 ; 2016)$.

The use of DSSCs as wearable solar cells unlocked a whole new concept of creating textile materials to enhance the power conversion efficiency, setting new challenges such as the adaptation of some materials used for the different components of DSSCs, like electrodes, electrolytes and so on.

Other technologies have also emerged in this field. Organic Solar Cells (OSCs) end application is roughly the same as the other-power small electronics through embodied photovoltaic cells-and offering a much more flexible material, extreme thinness, stretchability and biodegradability. 
In Timothy F. O'Connor experiment it was created a specialized wearable OSC with a $13 \mu \mathrm{m}$ thickness. The composition of this OSC is given in vertical layers created by the spin-coating mechanism over a PI adhesive substrate. On top of this primary compound, poly $(3,4-$ ethylenedioxythiophene): Poly (styrenesul fonate) (PEDOT: PSS), Polyethyleneimine (PEI) and P3HpT: PCBM were deposited. It was also possible to design (PEDOT: PSS) top-contacts, since this material acts both as the anode and the cathode and to establish the electrical contacts of the circuit silver paint was added. This solar cell is visually represented in Fig. 7 to better perceive the object at study O'Connor et al. (2016).

To prove the practicality of his solution, Timothy and his co-workers used the wearable OSC to power three different devices: A digital wristwatch, an LED and a portable battery (power bank). The LED and the watch were tested under an irradiance of $980 \mathrm{~W} / \mathrm{m}^{2}$ of natural sunlight, while the power bank was charge with a solar simulator that produced an irradiance of $1000 \mathrm{~W} / \mathrm{m}^{2}$, hence providing the $I(V)$ curves of the OSC for each different load. However, to produce a minimum voltage and current for each device, multiple OSCs were connected in series to achieve the specified values, which can be observed in Table 1 along with the values for the $I_{C C}$ and $V_{O C}$ O’Connor et al. (2016). Figure 8 presents Timothy's $I(V)$ characteristics.

In addition, two more objectives were targeted during the experiment, including the measurement of what the mechanical deformations of the OSCs impact the efficiency of the solar cell, as well as the impact of encapsulation on the efficiency.
Regarding the encapsulation of the solar cells, it was administered a $1 \mu \mathrm{m}$ layer of parylene $\mathrm{C}$ to some of the studied OSCs, along with a control group that was unprovided of such barrier. The goal was to analyze the efficiency decrease over time. Once out of the solar simulator, the efficiency was measured hour after hour until a total of five hours and the results presented a big decrease in the control group, because it only retained $42.5 \pm 3.3 \%$, while on the other hand the encapsulated cells retained $82.3 \pm 3.4 \%$.

Concerning the measurement of the mechanical deformations, the OSCs were compressed manually by approximately $75 \%$. To verify the changes to the behavior of the cell, the current density was registered along with its efficiency over a 1000 strain cycles, which is depicted in the Fig. 9a. The OSCs under strain were not encapsulated, which lead to a loss in efficiency not only by mechanical deformation but also under chemical degradation of the materials themselves. This means that materials that were not subjected to any type of strain or compression (mechanical) would automatically deteriorate because of the chemical compound's degradation, as seen in Fig. 9b O'Connor et al. (2016).

Current density-Voltage curve for the wearable OSC, throughout the strain stress test for 1000 cycles of compression.

Table 1: Timothy's experimental results for each examined device

\begin{tabular}{llllll}
\hline & Vmin & Imin & \# cells & VOC & ICC \\
\hline Wristwatch & $1.8 \mathrm{~V}$ & $100 \mu \mathrm{A}$ & 4 & $2.23 \mathrm{~V}$ & $0.5 \mathrm{~mA}$ \\
LED & $0.4 \mathrm{~V}$ & $1 \mathrm{~mA}$ & 8 & $1.125 \mathrm{~V}$ & $1.5 \mathrm{~mA}$ \\
Battery & NS & NS & 15 & $8 \mathrm{~V}$ & $0.3 \mathrm{~mA}$ \\
\hline
\end{tabular}
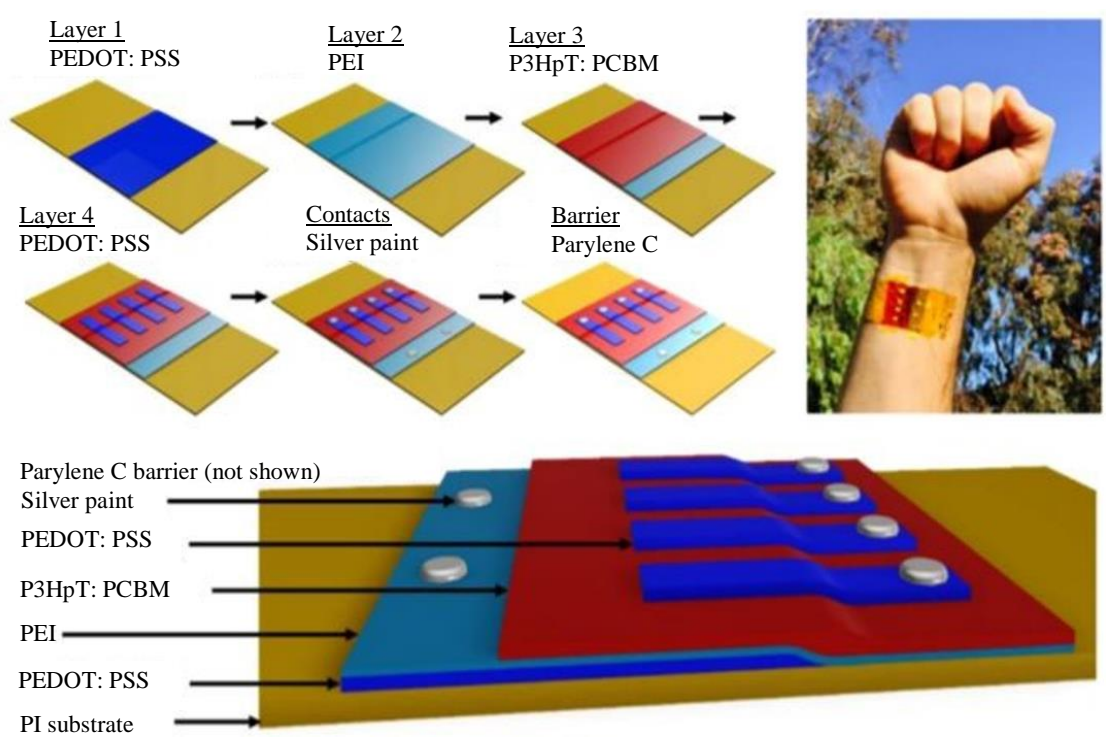

Fig. 7: Organic Solar Cell (OSC) utilized in Timothy F. O'Connor's experiment, composed of different organic and biodegradable materials, to allow the contact with human skin, O'Connor et al. (2016) 

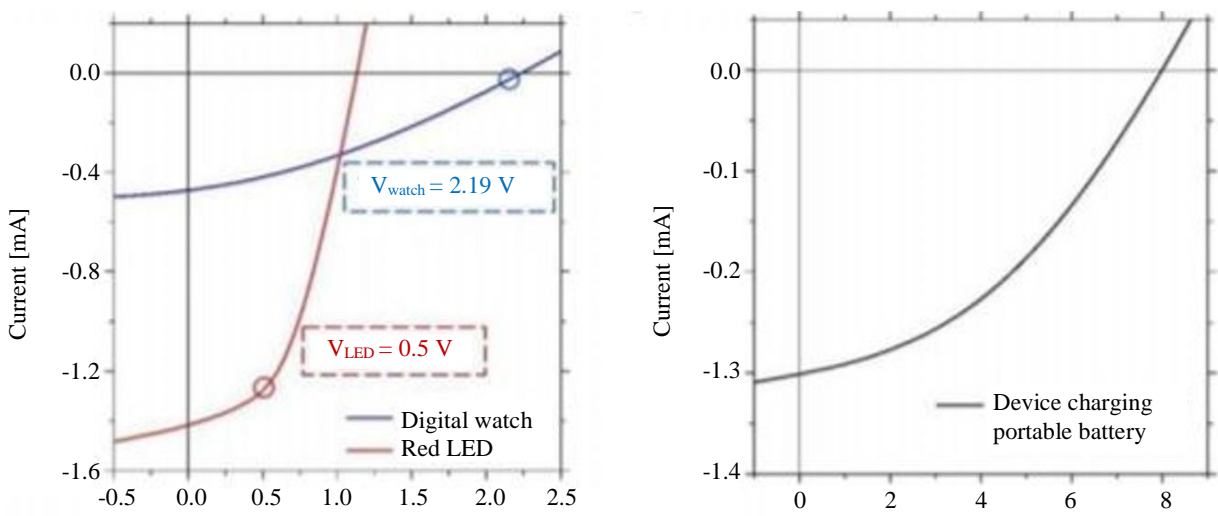

Fig. 8: $I(V)$ curves for the three examined devices, followed by the maximum power voltages of the LED and watch. To be noted that the portable battery was the only device that was charged inside the glove box (solar simulator), due to the fragility of the connected wires of all 15 cells, O'Connor et al. (2016)

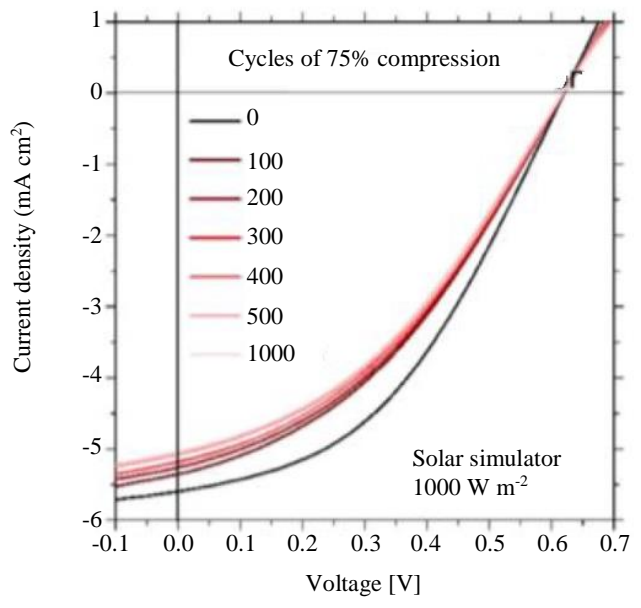

(a)

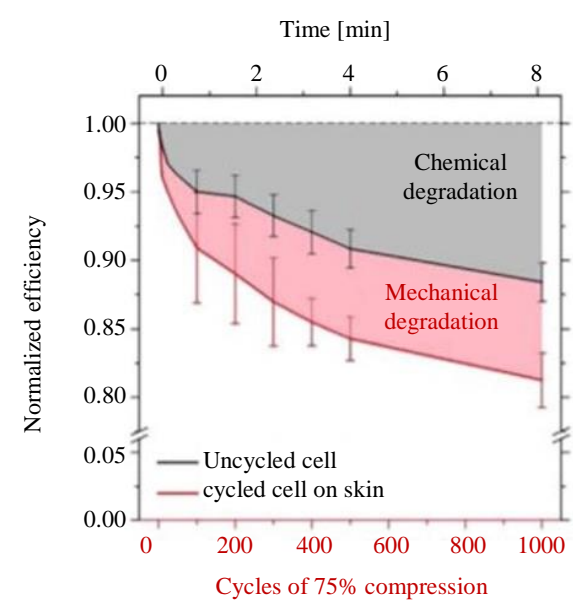

(b)

Fig. 9: Flexibility test of the wearable OSC, O'Connor et al. (2016); (a) Current density-Voltage curve for the wearable OSC, throughout the strain stress test for 1000 cycles of compression; (b) Normalized efficiency of the wearable OSC over 1000 cycles of $75 \%$ compressions (red) and the undeformed control cells (black) measured at the same cycle intervals

Another material that is very popular among the flexible photovoltaic cells is perovskite. This material has been coming up as one of the most promising alternatives to silicon cells, due to its relatively high efficiency growth throughout the years. For wearable applications, perovskite proves to be an advantageous semiconductor in solution processability, which means that is a good coating substrate for paper and plastics (dos Santos et al., 2021; Isabela et al., 2021).

Jae Wong Jung and his fellow co-workers developed a textile substrate from solution-processed perovskite derived from a Polyurethane (PU) layer, this way improving the wettability, processability and surface morphology of the textile. PU not only exhibits a hydrophilic behavior which is a plus side for the coating processes, but also acts as a barrier preventing any type of moisture through the textile substrate. The composition of the studied solar cell can be observed in Fig. 10 Jung et al. (2018).

As a substrate, it was used polyester, since it is a thermally durable fiber and, on top of it, PU layer is deposited, facilitating the printing of PEDOT: PSS over it. Given the fact, of this cell not being exactly the same as other traditional perovskite solar cells, carbon nanotubes were mixed into the PEDOT: PSS so it can improve the electrical conductivity. Later the $\mathrm{CH} 3 \mathrm{NH} 3 \mathrm{PbI} 3$ layer, also known as the Perovskite absorber layer, was added followed by the PCBM and a very thin silver electrode layer $(8 \mu \mathrm{m})$.

In conclusion of $J_{a e}$ Wong Jungs's experiment, the current density curves were plotted in Fig. 11 which allowed to register the $J_{S C}$ and $V_{O C}$ for different wavelengths, along with the efficiency. These results are shown in Table 2. 
With high efficiency perovskite solar cells, it is possible to create very creative and technological accessories or clothing with the main purpose of serving as an energy source to power small or low-voltage devices, as it can be seen in Fig. 12. Additionally, perovskite also presents an excellent conversion efficiency under indoor lighting, due to the fact of indoor lighting rounding 100-1000 lux, making indoor lighting a possibility for powering some wireless sensors or even smart phones, with a few of these cells Yang et al. (2019).

In order to recreate and develop more results in wearable PV applications the materials used in the future experiments will all be conducted using perovskite solar cells, as it is the only material in the laboratory that is accessible to perform further studies. The laboratory offers various types of solar cell materials, but none of them have the unique feature of flexibility unlike the perovskite to be studied in one of these applications. To become more familiar with this type of material and technology, in the following sections the state-of-art of perovskite is presented, mentioning not only the history of perovskite applications, but also the manufacturing and recycling procedures.

\section{Perovskite Material}

The perovskite material has in no doubt been in the spotlight for the last few years, as it emerges as one of the most efficient and low-cost energy materials in photovoltaic applications. One of the main features of the Perovskite Solar Cells (PSC) is its flexibility (Tang et al., 2017; Zhou et al., 2018; Isabela et al., 2021; dos Santos et al. 2021).

Currently, the PSC are composed of 5 layers:

- Tin-doped Indium Oxide (ITO) substrate or Fluorinedoped Tin Oxide (FTO) substrate

- Perovskite photoactive layer

- Hole Transport Layer/Material (HTL/HTM)

- $\quad$ Electron Transport Layer/Material (ETL/ETM)

- Metal electrode

These layers can be better observed in Fig. 13 .

The perovskite photoactive layer absorbs light, which leads to the generation of electron and hole pairs. These pairs are later separated and extracted into the ETM and HTM layers respectively through diffusion and once they reach the electrodes the PSC can be powered.

The perovskite material was discovered in the 19th century by Gustav Rose from a calcium titanate ore, but it is first use for photovoltaic applications, only came about in 1991, after O'Regan and Gratzel created a dyesensitized solar cell with a $7 \%$ efficiency. This sparked the arising of the PSCs with perovskite compounds. The crystalline structure of the perovskite is identical to the Calcium Titanate $\left(\mathrm{CaTiO}_{3}\right)$ structure with the general molecular formula $\mathrm{ABY}_{3}$, which corresponds to the way the molecules and ions are aligned. For instance, in the ions at use are usually methyl-ammonium $\left(\mathrm{CH}_{3} \mathrm{NH}_{3}{ }^{+}, \mathrm{MA}^{+}\right.$for short) and formamidine $\left(\mathrm{CH}_{3} \mathrm{CH}_{2} \mathrm{NH}_{3}{ }^{+}, \mathrm{FA}^{+}\right.$for short), in $\mathrm{B}$ typically it is required divalent metal ions like $\mathrm{Pb}^{2+}$ or $\mathrm{Sn}^{2+}$ and for $\mathrm{Y}$ it's used halide anions such as $\mathrm{I}^{-}, \mathrm{Br}^{-}$or $\mathrm{Cl}^{-}$ to bind with the previous A and B cations. Ali and Yashima (2005) Tang et al. (2017) Yang et al. (2019).

In the development of high efficiency PSCs, Kojima, Miyasaka and his co-workers, in 2009, tested the organicinorganic hybrid halide-based perovskite of the type $\mathrm{CH} 3 \mathrm{NH} 3 \mathrm{PbX} 3$ (for $\mathrm{X}$ it was used $\mathrm{I}^{-}$and $\mathrm{Br}^{-}$).

However, the results were not as surprising as it thought, since it was registered a maximum efficiency of $3.81 \%$ Kojima et al. (2009). One of the main sources of this disappointing outcome, was originated from the liquid electrolyte used for hole transportation. Despite these bad results, it was introduced a new type of material to this area of study and in 2012 the same type of material was used but it was now added more layers to provide a solid Electron and Hole Transport (ETL/HTL). This change achieved a $9.7 \%$ efficiency, for the first perovskite based solid-state mesoscopic hetero-junction. These materials helped free electrons and holes to be collected by each of their respective materials.

Table 2: Results for Jae Woong Jungs experiment for different wavelengths (s.a.,: Solvent annealing) Jung et al. (2018)

\begin{tabular}{lllll}
\hline & Voc $[\mathrm{V}]$ & JSC $[\mathrm{mAcm}-2]$ & $\eta[\%]$ & FF \\
\hline $450 \mathrm{~nm}$ & 0.62 & 7.88 & 1.75 & 0.35 \\
$600 \mathrm{~nm}$ & 0.82 & 12.18 & 5.17 & 0.50 \\
$600 \mathrm{~nm}$ (s.a.) & 0.88 & 12.44 & 5.72 & 0.51 \\
\hline
\end{tabular}

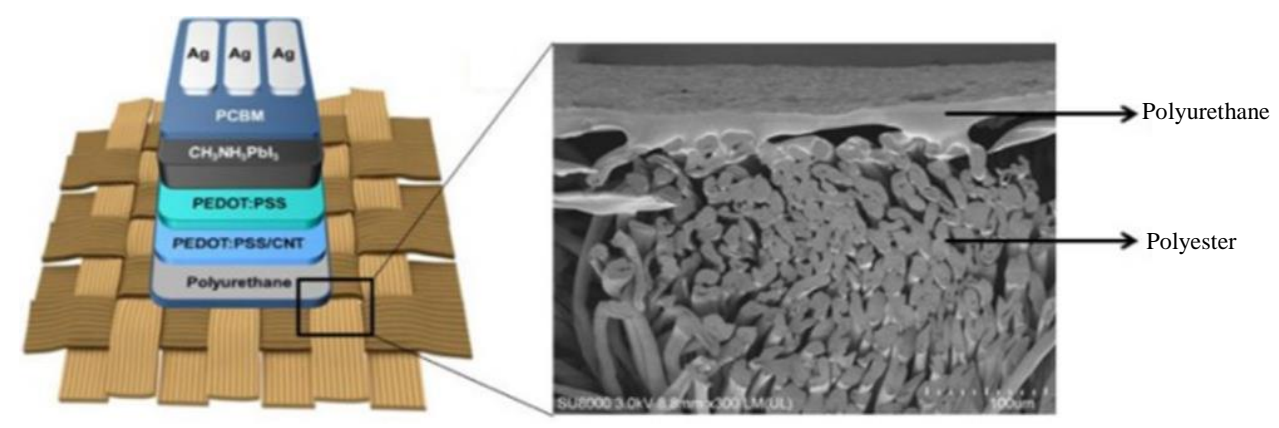

Fig. 10: Perovskite solar cell layer layout and composition of the substrate which the cell has deposited 


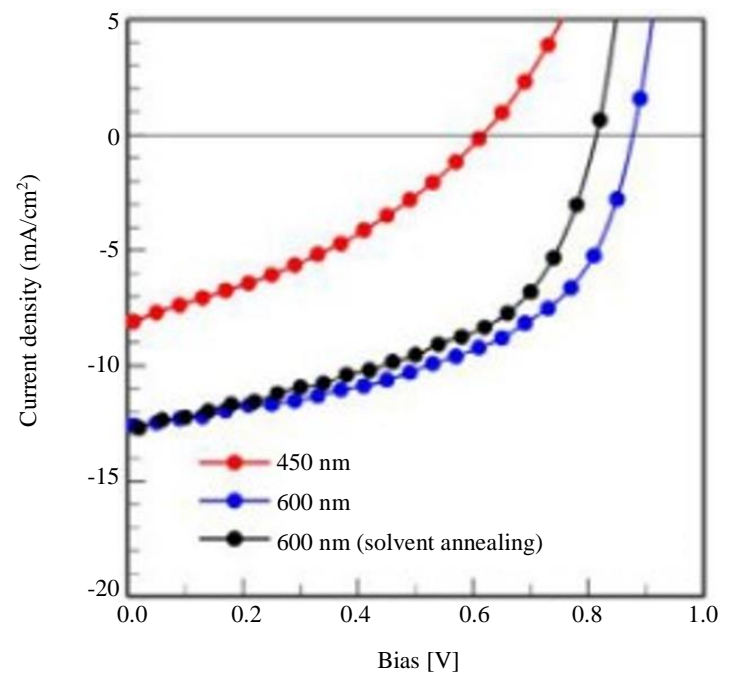

Fig. 11: Current density-voltage curves for the different tested wavelengths, Jung et al. (2018)
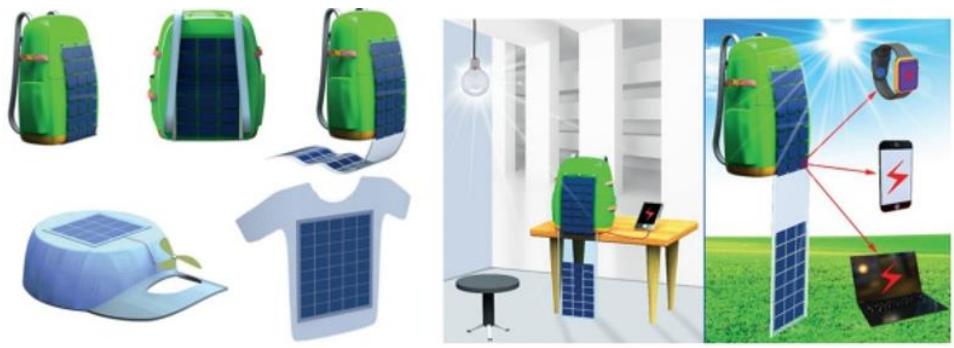

Fig. 12: Possible applications of wearable devices, followed by possible applicable functions for these cells, Yang et al. (2019)

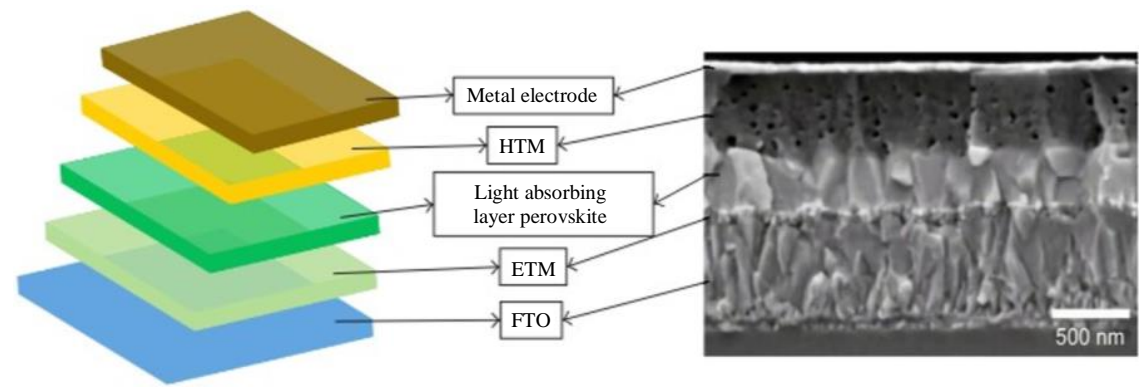

Fig. 13: Illustration of the perovskite hetero-junction layers paired with the cross-section Scanning Electron Microscopy (SEM) of the planar hetero-junction structure of PSCs, Zhou et al. (2018)

To build the ETL it is commonly used titanium dioxide $\left(\mathrm{TiO}_{2}\right)$, as well sometimes as a mesoporous oxide layer that plays a role in the transport of electrons, blocking holes and obstruct any sort of recombination of electron-hole pairs in the FTO substrate. For HTL, Spiro-OMeTAD is the chosen material for its electrical properties and helps the PSCs achieve the high PCE results that is so claimed for Kim et al. (2012); Tan et al. (2020); Tang et al. (2017).

The creation of this hetero-junction material was the tipping point for the research in PSC applications and continuous improvements in the power conversion efficiency. In 2016, some adjustments were made to increase the efficiency of the PSCs to $22.1 \%$.

PSCs have been quite notorious about its high efficiency conversion, however perovskite also packs a few more advantages along with it. One good example can be the high absorption coefficients and adjustable band gaps, which allowed the substitution of certain layers to increase a bigger absorption spectrum, for example the swap of FA ions with MA in triiodide PSCs extended the absorption range from 780 to $830 \mathrm{~nm}$. In 2016, researchers compared two PSCs with different compounds, one with 
tin and iodine and other with lead and iodine doped with bromine each with their own band gaps. Nonetheless the group came across once these cells are combined into another cell it was possible to absorb the whole visible light spectrum, enhancing the efficiency of future PSCs Tang et al. (2017); Yang et al. (2019).

At this rate, perovskite seems to be an uncontested material with little or no drawbacks, which is very untrue. PSCs have some drawbacks in the environmental area, which will be dealt with in a further section, but long-term operational stability is still a major issue with these types of cells. This lack of stability in the cell occurs when the organic compounds of the cell are exposed to moisture $\left(\mathrm{H}_{2} \mathrm{O}\right)$ or in contact with ultraviolet light or high temperatures, degrading the compound from the inside out Masitoh et al. (2021).

\section{Industrial Fabrication}

Perovskite also sets itself apart from the other photovoltaic materials through its fabrication and processing techniques. All the necessary materials that were discussed in the previous section have a relatively easy accessibility and great abundance. Perovskite presents a high tolerance to defects, providing a much larger number of PSCs at a much faster pace and, most importantly, lowering the production price, so it can be economically viable. In addition, the perovskite thin films can be altered to change its absorption range. So, to make sure that all the substrates are not negatively affected the fabrication procedures are completed at low temperatures $\left(150^{\circ} \mathrm{C}\right)$. This also allows the production of flexible solar cells since they do not tolerate high temperatures beyond $250^{\circ} \mathrm{C}$ Yang et al. (2019). Previously, all the flexible PSCs used for studies and efficiency tests were mainly designed and produced in laboratories. Nowadays, since the PCE has been increasing and matching the other photovoltaic materials, the desire to produce this new evolved solar cell in a more industrial environment has never been greater.

One-step deposition is the most common method produce thin layers of PSC. The MA or FA compounds are deposited through spin-coating, which technique is depicted in Fig. 14. Then it is mixed the rest of the other compounds on the turntable and it's taken to another spin applying the same method. While the plate is spinning, the materials are always under the annealing temperature and this temperature has to set to a certain value for it to reach the best PCE (usually about $100^{\circ} \mathrm{C}$ ) Ding et al. (2019); Yilbas et al. (2019).

At the moment, spin-coating is the most popular method for fabrication of thin films in lab-scale devices, through deposition. This method can hardly be replicated in an industrial format because this method wastes a lot of material that is ejected from the substrate once in rotation. Also, if the size of the substrate is too big, the high-speed spinning becomes more difficult.

Recently, the best way to reduce the pricing of perovskite and maximize its throughput is by the implementation of a Roll-to-Roll (R2R) production for PSCs. To reach such aspired goal, the fabrication method had to be switched to printing techniques, which were more compatible with R2R.

In a more traditional overview, $\mathrm{R} 2 \mathrm{R}$ processing is a fabrication practice that has its roots in the manufacturing background, with the intention of embedding, coating, printing, or laminating numerous applications onto a flexible rolled substrate material that is continuously passed on from one roller to another. As the materials pass on from roll to roll, different actions will take place between them, such as the ones mentioned above, in a chain of events that will lead to a final product. Essentially, this technique has vast variety of applications and sectors that require flexible material for completing a finished product Park et al. (2016). Covering from textiles and paper, all the way to electronics and PCB boards, the roll-to-roll mechanism has proven to be a very well-known technology in the industrial department and applying this very well-established mechanism to PSC fabrication can spark a great increase in its mass production, making the PSCs to reach a more competitive price in the market.

Currently, the R2R fabrication is starting to be more recognized as a possibility in the production of PSC in an industrial manor, promoting different types of techniques to manufacture these new panels, so to better visualize the fabrication procedure Fig. 15 exhibits a pilot solution provided by a few scientists lead by Young Yun Kim of what it looks like to establish a R2R PSC manufacture. The target of this pilot-scale $\mathrm{R} 2 \mathrm{R}$ machine, was to test the gravure printing technique they developed, which can deposit and pattern a desired layer at once through high precision, like a printer (Kim et al., 2019; Liedert et al., 2020).
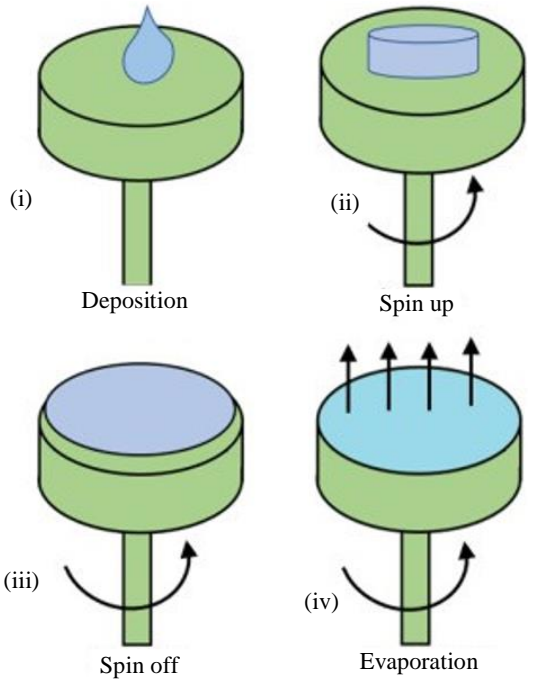

Fig. 14: (i) The material is deposited on the turntable (ii) the turntable start accelerating applying centrifugal force, thinning the layer (iii) the turntable decelerates (iv) throughout the process the plate will heat up and remove high volatile compounds and drying the rest of the substrate, Yilbas et al. (2019) 


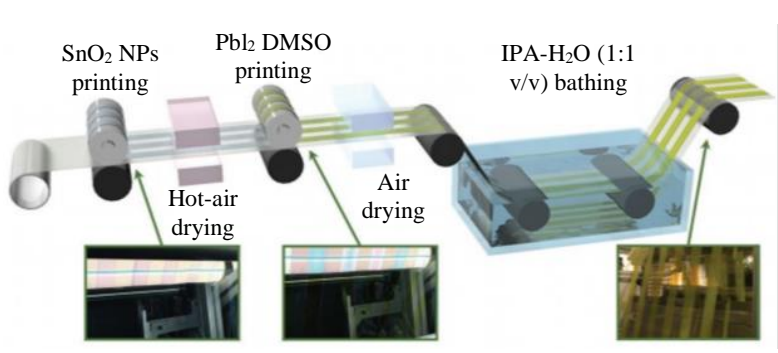

Fig. 15: Illustration of the roll-to-roll system for PSC production, Kim et al. (2019)

\section{Photovoltaic Waste, Recycling and Toxicity}

Nowadays, photovoltaic panels and solar energy production is one of the major hot topics in the green and sustainable cities of tomorrow, in order to ensure the wellbeing of the future generations of mankind. In this topic it will be focused initially the use of silicon as the worlds' prime material for solar cell production and its recycling process, so it can be possible to perform a comparison between the recyclability of perovskite versus silicon solar cells dos Santos et al. (2021); Isabela et al. (2021).

Production of clean energy came as a solution to reduce the impact of fossil fuel as an energy source (dos Santos et al., 2021; Isabela et al., 2021; Durão et al., 2020). Although its huge contribution to the reduction of the planet's carbon footprint, photovoltaic applications have their own life cycle. Once it has reached its end, the PV module or device starts to be seen as electronic waste. Throughout their lifetime, panels decrease their efficiency and need to be replaced by new ones, after a few decades. Most of the PV waste ends up in landfills and given the presence of numerous toxic materials, it can lead to a dangerous source of pollution, such as the pollution of ground waters. Despite the environmental hazardous materials, some of modules contain valuable metals such as Silver, Copper and Gold which can be extracted for re-fabrication purposes, therefore bringing an extra value for recycling these metals and materials Duarte et al. (2021); dos Santos et al. (2021); Durão et al. (2020).

This calls for the need to recycle this type of waste and luckily, this subject is already being taken into consideration by the European Commission, providing the Waste Electrical and Electronic Equipment (WEEE) Directive Lunardi et al. (2018).

Silicon waste is one of the main concerns when developing PV systems, because $94 \%$ of the solar cells produced use crystalline silicon, roughly translating into 400,000 tons of this material. The major problem at the table when it comes to silicon PV panel production is the high purity of the silicon itself. To produce a $\mathrm{Si}$ module, about $40 \%$ of it is lost in the wafer and multiwiring sawing processes or as its commonly designated Kerf loss Li et al. (2021).
Despite the importance of recycling and reusing used up silicon from old panels or industrial silicon waste, the procedures for rehabilitation are very energy demanding and economically impractical. High purity silicon manufacturing is a very energy intensive process and to apply recycling methods for the intensive production Deng et al. (2019).

Other applications do not entirely rely on the use of silicon as the prime material for solar cells and perovskite is one of them. Hybrid halide perovskite materials, has seen in the previous sections, continuously prove to be a market changing technology in the power conversion efficiency domain as an extremely efficient light harvester. The main reason for perovskite not to be considered a market solution is the existence of heavy metals such as lead $(\mathrm{Pb})$, a very toxic material for all living organisms, making it a deeply hazardous material to be in contact with humans and the environment.

Despite lead being a very dangerous material, there are two possible answers to solve this predicament. Firstly, the lead in the PSC can be replaced by other nontoxic alternatives of perovskite, for instance tin-based PSCs can be one of the best alternatives using lead-free PSCs, however the efficiency of these solar cells leaves a lot to be desired because the best recorded PCE rounds 9\% Mahajan et al. (2020).

On the other hand, for the advantageous high efficiency lead perovskite not to be gone to waste, it is possible to establish a recycling procedure to reuse the lead iodide, avoiding the disposal of this material Binek et al. (2016).

The recycling of $\mathrm{PbI}_{2}$ in PSCs as seen in Fig. 16, is done layer by layer, i.e., the layers are stripped one by one, starting from the gold electrodes at the top and only stopping at the FTO substrate. Each layer is stripped differently, for example in the case of Spiro-OMeTAD Hole Transport Layer (HTL), the material is submerged in a chlorobenzene bath, removing the HTL without removing the actual MAPbI3 perovskite layer.

To remove the perovskite layer must first be separated into methylammonium iodide MAI and PbI2, so it is used double distilled water to separate into these two compounds, obtaining the lead iodide in small concentration. To be considered legal, this concentration must be within legal values according to the country's responsible entity for such matters. $70 \mathrm{dm}^{2}$ of perovskite film yields around $600 \mathrm{mg}$ of $\mathrm{PbI}_{2}$, which is enough to prepare $2 \mathrm{dm}^{2}$ of recycled $\mathrm{MAPbI}_{3}$, of which the loss of material comes in the preparation of the films, due to spin-coating.

The efficiency is quite remarkable as well as it can be seen in Fig. 17 along with the relevant parameters. The recycled cell contained some impurities, hence achieving a worse result, which lead to a recrystallization of the cell improving its performance Binek et al. (2016). 


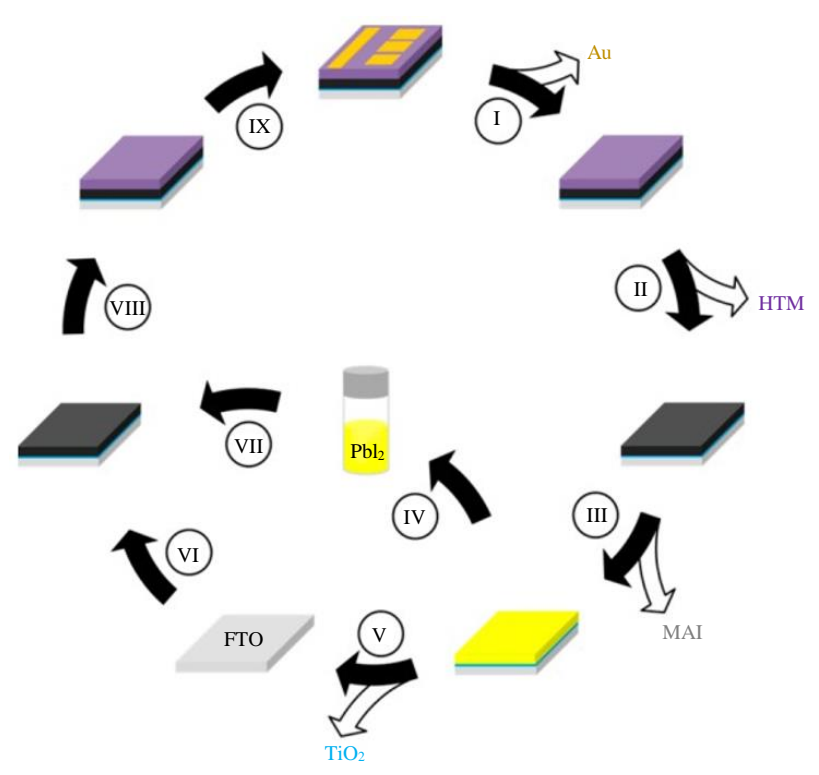

Fig. 16: Recycling procedure for PSCs, proposed by Andreas Binek (I) Removal of Au contact with adhesive tape. (II) Removal of HTM. (III) Transformation of the perovskite into MAI and $\mathrm{PbI}_{2}$. (IV, V) Removal of $\mathrm{TiO}_{2}$ and $\mathrm{PbI}_{2}$ using DMF. (VI) Preparation of a new $\mathrm{TiO}_{2}$ film. (VII) Formation of the perovskite film on recycled FTO and lead iodide. (VIII) Preparation of the HTM layer. (IX) Gold top electrode, Binek et al. (2016)

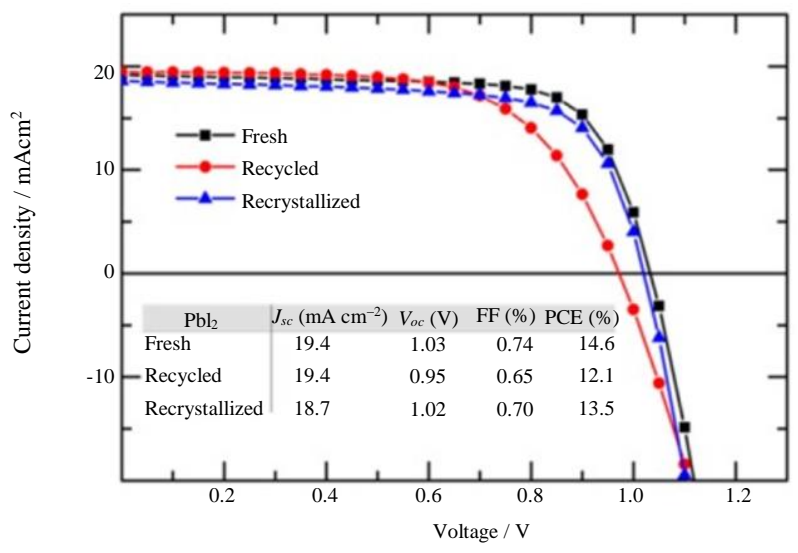

Fig. 17: Comparison of the J-V characteristics between recycled PSCs and original PSCs. The main parameters for comparison are also presented in the graph, Binek et al. (2016)

On a more economical point of view, the perovskite recycling procedure cost is still complicated to determine since there are many variables at stake. Essentially, it is still complicated to set a value for the actual cost of perovskite solar cells' mass production and recycling at an industrial level Augustine et al. (2019).

Firstly, it is still complicated to set a value for the actual cost of perovskite solar cells' mass production and recycling at an industrial level.

Another undetermined, yet inescapable variable is the cost and procedure for transportation and dismantling of the solar panels, because the operations have to be in accordance with international electronic waste disposal laws and may be different for each region/country.

Fortunately, the recycling procedures can all be developed under low temperatures, which is a huge deal, once compared with silicon's high temperature production and recycling procedures, making the process much less energy dependent, thus achieving a much smaller price.

\section{Conclusion}

As it was demonstrated during this article, perovskite technology has grown a lot in the past years 
in the power conversion domain. This breakthrough in PSC's efficiency, has open up a lot of windows for innovative solutions in this field that previously were not possible to conceive. While perovskite's flexible features were also a great help, wearable solar cell applications are not that far from fiction.

Also, it is shown that wearable photovoltaic applications have become more real, a necessary topic to be addressed and an interesting application field for photovoltaic technology.

\section{Acknowledgement}

This work was supported in part by FCT/MCTES through national funds and in part by cofounded EU funds under Project UIDB/EEA/50008/2020.

Also, this work was supported by FCT under the research grant UI/BD/151091/2021.

\section{Author's Contributions}

Afonso da Silva Ravasco: Was responsible to write the original draft.

João Paulo N. Torres: Is Afonso's Supervisor, he was responsible to analyze the results and to edit the final manuscript. Also, he organized and stablish the study goals.

Ricardo A. Marques Lameirinhas: Was responsible to analyze the results, to review and to edit the final manuscript. Also, he helped to organize and stablish the study goals.

\section{Ethics}

This article is original and contains unpublished material. The authors have read and approved this manuscript and no ethical issues are involved.

\section{References}

Ali, R., \& Yashima, M. (2005). Space group and crystal structure of the perovskite CaTiO3 from 296 to 1720 K. Journal of Solid State Chemistry, 178(9), 2867-2872. https://doi.org/10.1016/j.jssc.2005.06.027

Augustine, B., Remes, K., Lorite, G. S., Varghese, J., \& Fabritius, T. (2019). Recycling perovskite solar cells through inexpensive quality recovery and reuse of patterned indium tin oxide and substrates from expired devices by single solvent treatment. Solar Energy Materials and Solar Cells, 194, 74-82. https://doi.org/10.1016/j.solmat.2019.01.041

Batista, A., Fernandes, C. F., Pereira, J. and Paisana, J. (2012). Capítulo 1 - semicondutores. In LIDEL, editor, Fundamentos da Eletrónica, pages 1-91.

Bernardes, S., Lameirinhas, R. A. M., Torres, J. P. N., \& Fernandes, C. A. (2021). Characterization and Design of Photovoltaic Solar Cells That Absorb Ultraviolet, Visible and Infrared Light. Nanomaterials, 11(1), 78. https://doi.org/10.3390/nano11010078
Binek, A., Petrus, M. L., Huber, N., Bristow, H., Hu, Y., Bein, T., \& Docampo, P. (2016). Recycling perovskite solar cells to avoid lead waste. ACS Applied Materials and Interfaces, 8(20), 12881-12886. https://doi.org/10.1021/acsami.6b03767

Deng, R., Chang, N. L., Ouyang, Z., \& Chong, C. M. (2019). A techno-economic review of silicon photovoltaic module recycling. Renewable and Sustainable Energy Reviews, 109, 532-550. https://doi.org/10.1016/j.rser.2019.04.020

Ding, J., Han, Q., Ge, Q. Q., Xue, D. J., Ma, J. Y., Zhao, B. Y., \& Hu, J. S. (2019). Fully air-bladed high-efficiency perovskite photovoltaics. Joule, 3(2), 402-416. https://doi.org/10.1016/j.joule.2018.10.025

dos Santos, S. A. A., Torres, J. P. N., Fernandes, C. A., \& Lameirinhas, R. A. M. (2021). The impact of aging of solar cells on the performance of photovoltaic panels. Energy Conversion and Management: X, 10, 100082. https://doi.org/10.1016/j.ecmx.2021.100082

Duarte, F., Torres, J. P. N., Baptista, A., \& Marques Lameirinhas, R. A. (2021). Optical Nanoantennas for Photovoltaic Applications. Nanomaterials, 11(2), 422. https://doi.org/10.3390/nano11020422

Durão, B., N Torres, J. P., Fernandes, C. A., \& Marques Lameirinhas, R. A. (2020). Socio-economic study to improve the electrical sustainability of the north tower of Instituto superior Técnico. Sustainability, 12(5), 1923. https://doi.org/10.3390/su12051923

Engana Carmo, J., Neto Torres, J. P., Cruz, G., \& Marques Lameirinhas, R. A. (2021). Effect of the Inclusion of Photovoltaic Solar Panels in the Autonomy of UAV Time of Flight. Energies, 14(4), 876. https://doi.org/10.3390/en14040876

Huaroto, J. J., Suárez, E., \& Vela, E. A. (2020). Wearable mechatronic devices for upper-limb amputees. In Control Theory in Biomedical Engineering (pp. 205-234). Academic Press. https://doi.org/10.1016/B978-0-12-821350-6.00008-1

Isabela, C. B., Lameirinhas, R. A. M., Torres, J. P. N., \& Fernandes, C. A. (2021). Comparative study of the copper indium gallium selenide (CIGS) solar cell with other solar technologies. Sustainable Energy and Fuels, 5(8), 2273-2283. https://doi.org/10.1039/D0SE01717E

Jamalullail, N., Smohamad, I., Nnorizan, M., \& Mahmed, N. (2018, June). Enhancement of energy conversion efficiency for dye sensitized solar cell using zinc oxide photoanode. In IOP Conference Series: Materials Science and Engineering (Vol. 374, No. 1, p. 012048). IOP Publishing. https://doi.org/10.1088/1757-899X/374/1/012048

Jung, J. W., Bae, J. H., Ko, J. H., \& Lee, W. (2018). Fully solution-processed indium tin oxide-free textilebased flexible solar cells made of an organicinorganic perovskite absorber: Toward a wearable power source. Journal of Power Sources, 402, 327-332. https://doi.org/10.1016/j.jpowsour.2018.09.038 
Kim, H. S., Lee, C. R., Im, J. H., Lee, K. B., Moehl, T., Marchioro, A.,... \& Park, N. G. (2012). Lead iodide perovskite sensitized all-solid-state submicron thin film mesoscopic solar cell with efficiency exceeding 9\%. Scientific Reports, 2(1), 1-7. https://doi.org/10.1038/srep00591

Kim, Y. Y., Yang, T. Y., Suhonen, R., Välimäki, M., Maaninen, T., Kemppainen, A.,... \& Seo, J. (2019). Gravure-Printed Flexible Perovskite Solar Cells: Toward Roll-to-Roll Manufacturing. Advanced Science, 6(7), 1802094. https://doi.org/10.1002/advs.201802094

Kojima, A., Teshima, K., Shirai, Y., \& Miyasaka, T. (2009). Organometal halide perovskites as visiblelight sensitizers for photovoltaic cells. Journal of the American Chemical Society, 131(17), 6050-6051. https://doi.org/10.1021/ja809598r

Labouret, A., Villoz, M., Bal, J. and Hamand, J. (2010). Solar Photovoltaic Energy. Energy Engineering. Institution of Engineering and Technology.

Li, J., Lin, Y., Wang, F., Shi, J., Sun, J., Ban, B.,.. \& Chen, J. (2021). Progress in recovery and recycling of kerf loss silicon waste in photovoltaic industry. Separation and Purification Technology, 254, 117581. https://doi.org/10.1016/j.seppur.2020.117581

Liedert, C., Rannaste, L., Kokkonen, A., Huttunen, O. H., Liedert, R., Hiltunen, J., \& Hakalahti, L. (2020). Roll-to-roll manufacturing of integrated immunodetection sensors. ACS Sensors, 5(7), 20102017. https://doi.org/10.1021/acssensors.0c00404

Lunardi, M. M., Alvarez-Gaitan, J. P., Bilbao, J. I., \& Corkish, R. (2018). A review of recycling processes for photovoltaic modules. Solar Panels and Photovoltaic Materials. https://doi.org/10.5772/intechopen.74390

Mahajan, P., Datt, R., Tsoi, W. C., Gupta, V., Tomar, A., \& Arya, S. (2020). Recent progress, fabrication challenges and stability issues of lead-free tin-based perovskite thin films in the field of photovoltaics. Coordination Chemistry Reviews, 213633. https://doi.org/10.1016/j.ccr.2020.213633

Masitoh, H. E., Permatasari, F. A., Nuryadin, B. W., Aimon, A. H., \& Iskandar, F. (2021). Photoluminescence stability of $\mathrm{CH} 3 \mathrm{NH} 3 \mathrm{PbBr} 3$ perovskite nanoparticles by adding SiO2: Preliminary study. Materials Today: Proceedings, 44, 3309-3312.

https://doi.org/10.1016/j.matpr.2020.11.533

Melo, I., Torres, J. P. N., Fernandes, C. A. F., \& Lameirinhas, R. A. M. (2020). Sustainability economic study of the islands of the Azores archipelago using photovoltaic panels, wind energy and storage system. Renewables: Wind, Water and Solar, 7(1), 1-21. https://doi.org/10.1186/s40807-020-00061-8
Nanjappan, V., Liang, H. N., Wang, W., \& Man, K. L. (2017). Big Data: A Classification of Acquisition and Generation Methods. In Big Data Analytics for Sensor-Network Collected Intelligence (pp. 3-20). Academic Press. https://doi.org/10.1016/B978-0-12809393-1.00001-5

O’Connor, T. F., Zaretski, A. V., Savagatrup, S., Printz, A. D., Wilkes, C. D., Diaz, M. I.,... \& Lipomi, D. J. (2016). Wearable organic solar cells with high cyclic bending stability: Materials selection criteria. Solar Energy Materials and Solar Cells, 144, 438-444. https://doi.org/10.1016/j.solmat.2015.09.049

Park, J., Shin, K., \& Lee, C. (2016). Roll-to-roll coating technology and its applications: A review. International Journal of Precision Engineering and Manufacturing, 17(4), 537-550. https://doi.org/10.1007/s12541-016-0067-z

Soga, T. (2006). Fundamentals of solar cell. In Nanostructured Materials for Solar Energy Conversion (pp. 3-43). Elsevier. https://doi.org/10.1016/B978-044452844-5/50002-0

Tan, B., Raga, S. R., Rietwyk, K. J., Lu, J., Fürer, S. O., Griffith, J. C.,... \& Bach, U. (2021). The impact of spiroOMeTAD photodoping on the reversible light-induced transients of perovskite solar cells. Nano Energy, 82, 105658. https://doi.org/10.1016/j.nanoen.2020.105658

Tang, H., He, S., \& Peng, C. (2017). A short progress report on high-efficiency perovskite solar cells. Nanoscale Research Letters, 12(1), 1-8. https://doi.org/10.1186/s11671-017-2187-5

Yang, D., Yang, R., Priya, S., \& Liu, S. (2019). Recent advances in flexible perovskite solar cells: fabrication and applications. Angewandte Chemie International Edition, 58(14), 4466-4483. https://doi.org/10.1002/anie.201809781

Yilbas, B. S., Al-Sharafi, A., \& Ali, H. (2019). Self-Cleaning of Surfaces and Water Droplet Mobility. Elsevier.

Yun, M. J., Cha, S. I., Kim, H. S., Seo, S. H., \& Lee, D. Y. (2016). Monolithic-structured single-layered textile-based dye-sensitized solar cells. Scientific reports, 6(1), 1-8. https://doi.org/10.1038/srep34249

Yun, M. J., Cha, S. I., Seo, S. H., \& Lee, D. Y. (2014). Highly flexible dye-sensitized solar cells produced by sewing textile electrodes on cloth. Scientific reports, 4(1), 1-6. https://doi.org/10.1038/srep05322

Zhang, Y., Wu, Z., Li, P., Ono, L. K., Qi, Y., Zhou, J.,... \& Zheng, Z. (2018). Fully solution-processed TCO-free semitransparent perovskite solar cells for tandem and flexible applications. Advanced Energy Materials, 8(1), 1701569. https://doi.org/10.1002/aenm.201701569

Zhou, D., Zhou, T., Tian, Y., Zhu, X., \& Tu, Y. (2018). Perovskite-based solar cells: materials, methods and future perspectives. Journal of Nanomaterials, 2018. https://doi.org/10.1155/2018/8148072 